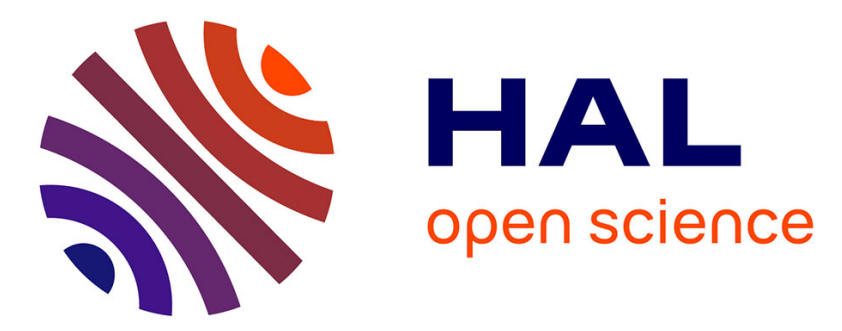

\title{
On the conditional dependence structure between oil, gold and USD exchange rates: Nested copula based GJR-GARCH model
}

\author{
Rihab Bedoui, Sana Braiek, Khaled Guesmi, Julien Chevallier
}

\section{To cite this version:}

Rihab Bedoui, Sana Braiek, Khaled Guesmi, Julien Chevallier. On the conditional dependence structure between oil, gold and USD exchange rates: Nested copula based GJR-GARCH model. Energy Economics, 2019, 80, pp.876 - 889. 10.1016/j.eneco.2019.02.002 . hal-03484738

\author{
HAL Id: hal-03484738 \\ https://hal.science/hal-03484738
}

Submitted on 20 Dec 2021

HAL is a multi-disciplinary open access archive for the deposit and dissemination of scientific research documents, whether they are published or not. The documents may come from teaching and research institutions in France or abroad, or from public or private research centers.
L'archive ouverte pluridisciplinaire HAL, est destinée au dépôt et à la diffusion de documents scientifiques de niveau recherche, publiés ou non, émanant des établissements d'enseignement et de recherche français ou étrangers, des laboratoires publics ou privés.

\section{()ㅜ(1)}

Distributed under a Creative Commons Attribution - NonCommerciall 4.0 International 


\section{On the Conditional Dependence Structure between Oil, Gold and USD Exchange rates: Nested Copula based GJR-GARCH Model}

Revised: November 2018

Rihab Bedoui, Sana Braiek, Khaled Guesmi, Julien Chevallier 


\begin{abstract}
Energy commodities and precious metals differ from other trading products. Both oil and gold prices are leading economic variables, and drive the evolution of the world economy. Since the US dollar is used as the primary currency of international crude oil and gold trading, the relationship between commodities, metals and exchange rates has become a major research agenda recently. Therefore, this study proposes a Nested copula-based GJR-GARCH model to explore the dependence structure between oil, gold, and the USD exchange rate. More importantly, a comparative framework based on two sub-periods is implemented to capture the co-movement during normal and crisis periods. Empirical results suggest that for both crisis periods the dependence between oil, gold and the USD exchange rate is stronger compared with the dependence during the untroubled period. Moreover, the co-movement is accelerated which is explained by the unusual movement of the USD during the global financial crisis of 2007-2009.
\end{abstract}

JEL classification: C14; G01; Q40.

Keywords: Oil; Gold; FX; Dependence structure; Nested Archimedean Copula; BiVaR. 


\section{Introduction}

The topic of energy prices has once again highlighted, with the recent surge in energy prices, especially oil prices. Plourde and Watkins (1998) and Regnier (2007) find that crude oil's price volatility is substantially higher than other energy products since the mid-1980s.

These increases become a principal concern for consumers, corporations, and governments. Most of the oil consumed in the world today move from one country to another. It is by far the largest single commodity in international trade, and the oil industry is one of the largest and most international of all industries in the world.

Crude oil prices is an important and sometimes determinant variable, for the economic policy makers of countries that have this commodity as a main source of energy, as well as in those where crude oil price is part of their energy matrix. In the majority, primary commodity prices are expressed in US Dollar, especially oil prices, not only in the commodity markets but also in many international organizations, such as in the IMF International Financial Statistics, or regarding indexes based on dollar prices. As such, oil prices are affected by inflation as well as real developments, and also by the value of the US dollar exchange rate.

The relationship between oil prices and economic fundamentals has roots in the pioneering work of Hamilton (1983). Hamilton's work established the link between oil price increases and the US business cycle. Several previous works by Throop (1993) and Zhou (1995) have evidenced a relationship between oil prices and exchange rate movements. In the case of the dollar, the link is generally found to be positive, which means that an increase in oil price goes with a dollar appreciation. Very few of these papers then try to ask which variable causes the other. That is the case for Amano and Van Norden (1998), who show that oil price is a primary driving factor of the long-term evolution of exchange rates in Germany, Japan, and the United States. Wu and al (2012) study the dynamic copula-based GARCH models to explore the dependence structure between the oil price and the US dollar exchange rate.

Precious metals especially gold are also expressed in US Dollar. Capie et al. (2005) which assess the role of gold as a hedge against the US dollar by estimating elasticities for a model of the responsiveness of gold to changes in the exchange rate. Capie et al. (2005) find that gold has in the past acted as an effective hedge. However, their approach takes the form of a single-equation model in which the independent variable, the exchange rate, is assumed to be unaffected by the time path of the dependent variable, the price of gold.

Both oil price, gold is leading economic variables, which drive the evolution of the world economy. Their changes profoundly affect international trade and economic activity in all countries. Baffes (2007), using annual data, examine the pass-through of crude oil price changes to the price of 35 internationally traded primary commodities. He finds that the price of precious metals, in particular, gold, responded strongly to the crude oil price. Through three volatility models from the generalized autoregressive conditional heteroskedasticity (GARCH) family, Hammoudeh et Yuan (2008) studied the impact of oil prices and interest rate shocks on gold returns and the volatility of gold returns. For daily data and using an exponential general autoregressive conditional heteroskedasticity (EGARCH) model, they find that oil price shocks had an insignificant effect on gold returns and reduced the volatility of gold returns.

Soytas et al. (2009) study, for Turkey, the relationship between oil prices and gold, silver and other macroeconomic variables using a vector autoregressive model to examine the short-run and long-run relationships between metal prices and the oil price. They report that the world oil price had no predictive power over precious metal prices in the Turkish economy.

Then, using impulse response functions and forecast error variance decompositions, Sari and al. (2010) analyze the effect of oil price shocks on precious metal returns and the US dollar/euro exchange rate they find that precious metal markets responded positively and significantly to oil prices, but only in the short-run, with the effect dissipating over the long run.

Narayan et al. (2010) examine the long-term relationship between gold and oil prices, finding that investors used gold as a hedge against inflation and that oil and gold could be used to predict 
prices mutually.

Using daily data, Zhang et Wei (2010) study the co-integration relationship, linear and non-linear Granger causality and price discovery for crude oil and gold markets. Their evidence indicates that crude oil and gold markets shared similar price trends, that there was a long-term equilibrium relationship between the two markets, that there was linear Granger causality from the oil price to the gold price and that there was no evidence of non-linear Granger causality.

More recently, Fratzscher et al. (2014) found bidirectional causality between the USD and oil price. There is a sizeable difference in the strength of transmission between direct and indirect channels. For instance, they find no direct effect of equity market on oil price, but a sizeable and significant effect via shocks on interest rates and risk. Similarly, the effects of shocks on both oil price and the US dollar are stronger than the direct effects. This result is important as it suggests that the transmission of shocks on financial markets to and from oil price is not uni-directional and limited to individual asset prices, but that the transmission process is complex and often occurs indirectly via third asset markets. Drachal (2016) addresses time variation in predictability by adopting a Dynamic Model Averaging framework for predicting the spot price of oil. He finds exchange rates to be important predictors between 1995 and 2000 and after 2005, while their relative importance diminishes between 2000 and 2005 .

The dependence between gold, oil and the exchange rate have received much attention recently from investors, traders, policy-makers and producers, partly because of the recent flare-up in their prices, increases in their economic uses and synchronization of their movement's. Their relationships have even attracted the attention of laypersons. These commodities are included in the commodity portfolios of most serious individual and institutional investors. They can be related because they are used as hedges by investors and traders, moving from dollar-denominated soft assets such as stocks to dollar-denominated physical assets such as oil and precious metals. Moreover, increases in oil prices may lead to power shortages which affect the production of precious metals as is the case in South Africa.

Using copula models (after cleaning the time series based on the AR-GARCH family), this paper extends the literature by simultaneously examining relationships among oil, gold, and foreign exchange from January 2000 to December 2017. Sub-period decomposition is considered as robustness checks. The full sample goes from January 3, 2000, to December 21, 2017. The crisis period ranges from July 16, 2007, to December 30, 2011.

The econometric approach unfolds in several steps. First, we generate residuals from the daily returns of GJR-GARCH models. Second, we examine the dependence parameters for five bivariate copulas across a network of 17 pairs of series (for which the Student- $t$ model is found to provide the best fit). Our empirical study begins with the bivariate dependence using the Elliptical and Archimedean copulas. Then, we move to the multivariate dependence using more flexible tool which is the nested copula. As our objective is to study the behavior of the co-movement between oil, gold, and FX during two sub-periods, the addition of the BiVaR consists in another step forward in analyzing the co-movement between different pairs (see Cousin and Di Bernardino, 2013). The contribution to the literature is that all three variables are considered simultaneously.

Relationships between gold and FX, gold and oil, and oil and FX have been studied, but this is the first attempt - to our best knowledge - that combines the three variables using a nested copula model. The economic rationale applies to an entity that produces gold, and exchanges currency to buy oil (or another entity that sells oil, has an FX portfolio and considers using gold to hedge the risk of the oil and FX portfolio). Such entities would be interested in the Value-at-Risk of their respective portfolios. Therefore, the article conveys interesting implications in portfolio management and risk management.

This paper differs from similar previous studies in several aspects. First, most of research papers focus on bilateral linkages such as oil vs stock markets (Jones and Kaul, 1996; Arouri et al., 2012; Mollick and Assefa, 2013), oil price vs gold price (Ewing and Malik, 2013), gold prices vs stock markets (Gaur and Bansal, 2010; and Le and Chang, 2012), oil price vs exchange rates (Basher et al., 2012) and other on trilateral linkages such as oil price, exchange rates and stock prices (Olugbenga, 
2012; Fratzscher et al., 2014).

Our research is undeniably novel in several perspectives. The first and foremost point involves our analytical examine on the dependence between USD exchange rates, gold and the fluctuation of crude oil prices. This idea appears at first glance to generate many appealing results, brings interesting discussions and offers economic importance. Unfortunately, a little attention has been paid to gain deeper insight into this direction. We are not the pioneers, but we are highly intrigued by this puzzle and determine to be dedicated to addressing this challenge theoretically and empirically. Secondly, another striking feature of our study relates to a thorough comparison about differences in each period, troubled and untroubled period. Thirdly, from our knowledge, none of earlier related work has been carried out on the three variables together. Likewise, a very little care has been taken to the linkage between Norwegian USD exchange rate and oil prices after the 2000s. Nonetheless, this period is of paramount importance and should be placed emphasis.

Constructing multivariate conditional distributions return series has been a major research agenda recently. To shed light in the co-movement between oil, gold, and USD exchange rates, a Nested copula-GARCH model is proposed which combine the use of GARCH models and a copula function to allow flexibility on the choice of marginal distributions and dependence structures. The empirical investigation uses daily log-returns of oil prices, gold and USD exchange rates over the period from January 4, 2000, to December 21, 2017. Then, our study period will be divided into two sub-periods: the overall period and crisis period. Our finding will be crucial because in our knowledge this is the first work that joins these three variables together and studying their dependence with Hierarchical Archimedean copula function. Moreover, using a CML method, we estimated the parameters of the copula and validated the choice with the goodness-of-fit test. Results suggest that for the crisis period the co-movement between variables is accelerated which is caused by the unusual movements of USD exchange rates during the subprime of 2007. Such information is crucial for investors when managing their financial portfolios.

We structure the rest of the article as follows. Section 2 describes the empirical methodology. In particular, we elaborate on the hierarchical dependence structure with the Nested Archimedean Copula model. Section 3 presents empirical results. Section 4 provides a discussion. Section 5 concludes the paper. 


\section{Methodology}

\subsection{Margins model with AR-GARCH}

Generalized Autoregressive Conditional Heteroskedastic GARCH models have become important in the analysis of time series data, particularly in financial applications when the goal is to analyze and forecast volatility. For this purpose, we describe functions for simulating, estimating and forecasting various univariate GARCH-type time series models in the conditional variance and an ARMA specification in the conditional mean.

We describe the mean equation of a univariate time series $x_{t}$ by the process:

$$
X_{t}=E\left(x_{t} \mid \Omega_{t-1}\right)+\epsilon_{t}
$$

where $\mathrm{E}(-)$ denotes the conditional expectation operator, $\Omega_{t-1}$ the information set at time $t-1$, and $\epsilon_{t}$ the innovations or residuals of the time series. $\epsilon_{t}$ describes uncorrelated disturbances with zero mean and plays the role of the unpredictable part of the time series. In the following, we model the mean equation as an ARMA process, and the innovations are generated from a GARCH process.

ARMA Mean Equation The $\operatorname{ARMA}(m, n)$ process of auto-regressive order $m$ and moving average order $\mathrm{n}$ can be described as:

$$
x_{t}=\mu+\sum_{i=1}^{m} \alpha_{i} x_{t-i}+\sum_{j=1}^{n} b_{j} \epsilon_{t-j}+\epsilon_{t}=\mu+a(B) x_{t}+b(B) \epsilon_{t}
$$

with mean $\mu$, autoregressive coefficients $a_{i}$ and moving average coefficients $b_{i}$. Note, that the model can be expressed in a quite comprehensive form using the backshift operator $B$ defined by $B\left(x_{t}\right)=$ $x_{t-1}$. The functions $a(B)$ and $b(B)$ are polynomials of degree $m$ and $n$ respectively in the backward shift operator $B$. If $\mathrm{n}=0$ we have a pure autoregressive process and if on the other hand $m=0$ we have a pure moving average process. The ARMA time series is stationary when the series $a(B)$, which is the generating function of the coefficients $a_{i}$, converges for $|B|<1$ that is, on or within the unit circle.

GARCH Variance Equation The mean equation cannot take into account for heteroskedastic effects of the time series process typically observed in the form of fat tails, as clustering of volatilities, and the leverage effect. In this context, Engle [1982] introduced the Autoregressive Conditional Heteroskedastic model, named ARCH, later generalized by Bollerslev [1986], named GARCH. The $\epsilon_{t}$ terms in the ARMA mean equation (2) are the innovations of the time series process. Engle [1982] defined them as an autoregressive conditional heteroscedastic process where all $\epsilon_{t}$ are of the form :

$$
\epsilon_{t}=z_{t} \sigma_{t}
$$

where $z_{t}$ is an iid process with zero mean and unit variance. Although $\epsilon_{t}$ is serially uncorrelated by definition its conditional variance equals $\sigma_{t}^{2}$ and, therefore, may change over time.

The variance equation of the $\operatorname{GARCH}(\mathrm{p}, \mathrm{q})$ model can be expressed as:

$\epsilon_{t}=z_{t} \sigma_{t}$

$z_{t} \sim D_{\vartheta}(0,1)$

$$
\sigma_{t}^{2}=\omega+\sum_{i=1}^{q} \alpha_{i} \epsilon_{t-i}^{2}+\sum_{j=1}^{p} \beta_{j} \sigma_{t-j}^{2}=\omega+\alpha(B) \epsilon_{t-1}^{2}+\beta(B) \sigma_{t-1}^{2}
$$

where $D_{\vartheta}(0,1)$ is the probability density function of the innovations or residuals with zero mean and unit variance. Optionally, $\vartheta$ are additional distributional parameters to describe the skew and the shape of the distribution.

The $\operatorname{AR}(1)-G A R C H(1,1)$ model with $r_{t}$ the return series in date $t$ can be written as: 


$$
\begin{gathered}
r_{t}=a_{0}+a_{1} r_{t-1}+\epsilon_{t} \\
\epsilon_{t}=\sqrt{h_{t}} \cdot z_{t} \\
h_{t}=\omega+\alpha \epsilon_{t-1}^{2}+\beta h_{t-1}
\end{gathered}
$$

\subsection{Copula and Dependence}

Copulas are defined as: functions that join one-dimensional distribution functions together to form multivariate distribution functions (Sklar 1959). Copulas not only solve the non-linear, non-elliptical problems, but also extend the bivariate world to multivariate dimension which gives us the ability to contain all the marginal distribution as a whole dependence structure.

Sklar's theorem states that any multivariate distribution can be factored into the marginal cumulative distributions and a copula function describing the dependence between the components.

A d-variate copula $C\left(u_{1}, \ldots, u_{d}\right)$ is a cumulative distribution function (cdf) with uniform marginals on the unit interval(Joe (1997) and Nelsen (2006)). If $F_{j}\left(y_{j}\right)$ is the CDF of a univariate continuous random variable $Y_{j}$, then $C\left(F_{1}\left(y_{1}\right), \ldots, F_{d}\left(y_{d}\right)\right)$ is a d-variate distribution for $Y=\left(Y_{1}, \ldots, Y_{d}\right)$ with marginal distributions $F_{j}, j=1, \ldots, d$. Conversely, if $H$ is a continuous d-variate cdf with univariate marginal cdfs $F_{1}, \ldots, F_{d}$, then there exists a unique d-variate copula $\mathrm{C}$ such that:

$$
F(Y)=C\left(F_{1}\left(y_{1}\right), \ldots, F_{d}\left(y_{d}\right)\right), \forall Y=\left(y_{1}, \ldots, y_{d}\right) .
$$

The corresponding density is:

$$
f(Y)=\frac{\partial^{d} F(Y)}{\partial y_{1} \ldots \partial y_{d}}=\frac{\partial^{d} C\left(F_{1}\left(y_{1}\right), \ldots, F_{d}\left(y_{d}\right)\right)}{\partial u_{1} \ldots \partial u_{d}} * f_{1}\left(y_{1}\right) \ldots f_{d}\left(y_{d}\right)=c\left(F_{1}\left(y_{1}\right), \ldots, F_{d}\left(y_{d}\right)\right) \prod_{j=1}^{d} f_{j}\left(y_{j}\right)
$$

where $f_{j}, j=1, \ldots$, dare the corresponding marginal densities.

Generally speaking, there are many types of copulas namely: Elliptical copula, Archimedean copulas, Placket Copula, and Nested Archimedean Copulas. Each of them has their family members and distinguishing properties. The elliptical copulas are known to perform better on systematic dependence structure problems. They constitute Gaussian copula and student t-copula. Archimedean copulas namely: Clayton, Gumbel, Frank and Joe copula capture lower tail dependence and upper tail dependence respectively (Alexander 2008).

The class of nested Archimedean copulas was first considered in Joe (1997) in the three and fourdimensional case and later by McNeil (2008) in the general d-dimensional case. McNeil (2008) and Hofert (2011a) derive an explicit stochastic representation for nested Archimedean copulas which allows for a fast sampling algorithm of nested Archimedean copulas similar to the Marshall-Olkin algorithm for Archimedean copulas; (Marshall and Olkin (1988)), Hofert (2011b) provides efficient sampling strategies for the most important ingredients to this algorithm, the random variables responsible for introducing hierarchical dependencies.

Gaussian Copula The Gaussian Copula (or Normal Copula) is one of the most standard copula in finance and risk management due to its elegance and numerical convenience. It was first introduced in financial modeling by David X. Li. The bivariate normal copula for all $u, v \in[0,1]$ is defined by:

$$
C(u, v)=\int_{-\infty}^{\varphi^{-1}(u)} \int_{-\infty}^{\varphi^{-1}(v)} \frac{1}{2 \pi \sqrt{1-\rho^{2}}} \exp \left(-\frac{s^{2}-2 \rho s t+t^{2}}{2\left(1-\rho^{2}\right)}\right) d s d t
$$

Here, $\varphi$ represents the univariate standard distribution function and $\rho$ is the linear correlation coefficient restricted to the interval $[-1,1]$. 
Student-t Copula The bivariate Student-t Copula is defined by:

$$
C(u, v)=\int_{-\infty}^{t_{\nu}^{-1}(u)} \int_{-\infty}^{\nu^{-1}(v)} \frac{1}{2 \pi \sqrt{1-\rho^{2}}} \exp \left(-\frac{s^{2}-2 \rho s t+t^{2}}{2\left(1-\rho^{2}\right)}\right)^{-\frac{\nu+2}{2}} d s d t
$$

where $t_{\nu}^{-1}(u)$ denotes the inverse of the CDF of the standard univariate Student-t distribution with $\nu$ the degrees of freedom and $\rho$ is the linear correlation coefficient. This copula has received much attention for modeling financial returns for its ability to capture the extreme values, a phenomenon typically observed in the series of financial returns. Indeed, the Student copula allows dependence symmetric tails, unlike the normal copula that does not allow the dependence of the copula tail.

The Archimedean class of copulas is popular in empirical applications (Genest and MacKay, 1986 and Nelsen, 2006). This class of copulas includes a whole suite of closed-form copulas that cover a wide range of dependency structures, including comprehensive and non-comprehensive copulas, radial symmetry and asymmetry, and asymptotic tail independence and dependence. The class is very flexible and easy to construct.

Further, the asymmetric Archimedean copulas can be flipped to generate new copulas (Venter(2001)). Archimedean copulas are constructed based on an underlying continuous convex decreasing generator function $\varphi$ from $[0,1]$ to $[0, \infty]$ with the following properties:

- $\varphi(1)=0$

- $\varphi(t)<0$

- $\varphi(t)>0$ for all $0<t<1\left(\varphi^{\prime}(t)=\frac{\partial \varphi}{\partial t} ; \varphi^{\prime \prime}(t)=\frac{\partial^{2} \varphi}{\partial^{2} t}\right)$

We assume that $\varphi(0)=\infty$, so that an inverse $\varphi^{-1}$ exists. With these preliminaries, we can generate bivariate Archimedean copulas as:

$$
C_{\theta}\left(u_{1}, u_{2}\right)=\varphi^{-1}\left[\varphi\left(u_{1}\right)+\varphi\left(u_{2}\right)\right]
$$

where the dependence parameter $\theta$ is embedded within the generator function. Note that the above expression can also be equivalently written as:

$$
\varphi\left[C_{\theta}\left(u_{1}, u_{2}\right)\right]=\left[\varphi\left(u_{1}\right)+\varphi\left(u_{2}\right)\right]
$$

The useful result for Archimedean copulas is that the expression for Kendalls $\tau$ in can be written in the following simple form (Genest and Mackay, (1986) or Embrechts and al., (2002) for a derivation):

$$
\tau=1+4 \int_{0}^{1} \frac{\varphi(t)}{\varphi^{\prime}(t)} d t
$$

Clayton Copula The Clayton copula has the generator function $\varphi(t)=(1 / \theta)\left(t^{-\theta}-1\right)$, giving rise to the following copula function :

$$
C_{\theta}\left(u_{1}, u_{2}\right)=\left(u_{1}^{-\theta}+u_{2}^{-\theta}-1\right)^{-1 / \theta}, 0 \prec \theta \prec \infty .
$$

The above copula, proposed by Clayton (1978), cannot account for negative dependence. It attains the Frechet upper bound as $\theta \rightarrow \infty$, but cannot achieve the Frechet lower bound. 
Frank copula The Frank copula, proposed by Frank (1979), is the only Archimedean copula that is comprehensive in that it attains both the upper and lower Frechet bounds, thus allowing for positive and negative dependence. It is radially symmetric in its dependence structure and imposes the assumption of asymptotic independence. The generator function is $\varphi(t)=-\ln \left[\left(e^{-\theta t}-1\right)\left(e^{-\theta}-1\right)\right]$, and the corresponding copula function is given by:

$$
C_{\theta}\left(u_{1}, u_{2}\right)=-\frac{1}{\theta}\left(1+\frac{\left(e^{-\theta u_{1}}-1\right)\left(e^{-\theta u_{2}}-1\right)}{\left(e^{-\theta}-1\right)}\right)
$$

Gumbel Copula The Gumbel copula, first discussed by Gumbel (1960) and sometimes also referred to as the Gumbel-Hougaard copula, has a generator function given by $\varphi(t)=(-\ln t)^{\theta}$. The form of the copula is provided below:

$$
C_{\theta}\left(u_{1}, u_{2}\right)=\exp \left(-\left[\left(-\ln u_{1}\right)^{\theta}+\left(-\ln u_{2}\right)^{\theta}\right]^{1 / \theta}\right), 1 \leq \theta \prec \infty .
$$

Like the Clayton copula,the Gumbel copula cannot account for negative dependence, but attains the Frechet upper bound as $\theta \rightarrow \infty$.

Joe copula The Joe copula, introduced by Joe $(1993,1997)$, has a generator function $\varphi(t)=$ $-\ln \left[1-(1-t)^{\theta}\right]$ and takes the following copula form:

$$
C_{\theta}\left(u_{1}, u_{2}\right)=1-\left[\left(1-u_{1}\right)^{\theta}+\left(1-u_{2}\right)^{\theta}-\left(1-u_{1}\right)^{\theta}\left(1-u_{2}\right)^{\theta}\right]^{1 / \theta}, 1 \leq \theta \prec \infty .
$$

The Joe copula is similar to the Clayton copula. It cannot account for negative dependence. It attains the Frechet upper bound as $\theta \rightarrow \infty$, but cannot achieve the Frechet lower bound.

Nested Archimedean Copula The class of nested Archimedean copulas was first considered in Joe (1997) in the three- and four-dimensional case and later by McNeil (2008) in the general ddimensional case. McNeil (2008) and Hofert (2011a) derive an explicit stochastic representation for nested Archimedean copulas which allows for a fast sampling algorithm of nested Archimedean copulas similar to the MarshallOlkin algorithm for Archimedean copulas; (Marshall and Olkin (1988)),Hofert (2011b) provides efficient sampling strategies for the most important ingredients to this algorithm, the random variables responsible for introducing hierarchical dependencies.

Regarding inference, Nested Archimedean copula recently gained interest since they generalize the well- known class of Archimedean Copulas to allow for partial asymmetry. A disadvantage of Archimedean copula is the fact that the multivariate dependency structure is very restricted, since it typically depends on a single parameter of the generator function $\varphi$. Moreover, the rendered dependency is symmetric with respect to the permutation of variables, i.e., the distribution is exchangeable. Hierarchical Archimedean Copulas (also called Nested Archimedean copula) overcome this problem by considering the compositions of simple Archimedean copula.

For example, the special case of HAC fully nested copula can be given by:

$$
\begin{gathered}
C\left(u_{1}, \ldots, u_{d}\right)=C_{1}\left\{C_{2}\left(u_{1}, \ldots, u_{d-1}\right), u_{d}\right\}=\varphi_{1}\left\{\varphi_{1}^{-1} \circ C_{2}\left(u_{1}, \ldots, u_{d-1}\right)+\varphi_{1}^{-1}\left(u_{d}\right)\right\} \\
C\left(u_{1}, \ldots, u_{d}\right)=\varphi_{1}\left\{\varphi_{1}^{-1} \circ \varphi_{2}\left(\varphi_{2}^{-1} C_{3}\left(u_{1}, \ldots, u_{d-2}\right)+\varphi_{2}^{-1}\left(u_{d-1}\right)\right)+\varphi_{1}^{-1}\left(u_{d}\right)\right\}
\end{gathered}
$$



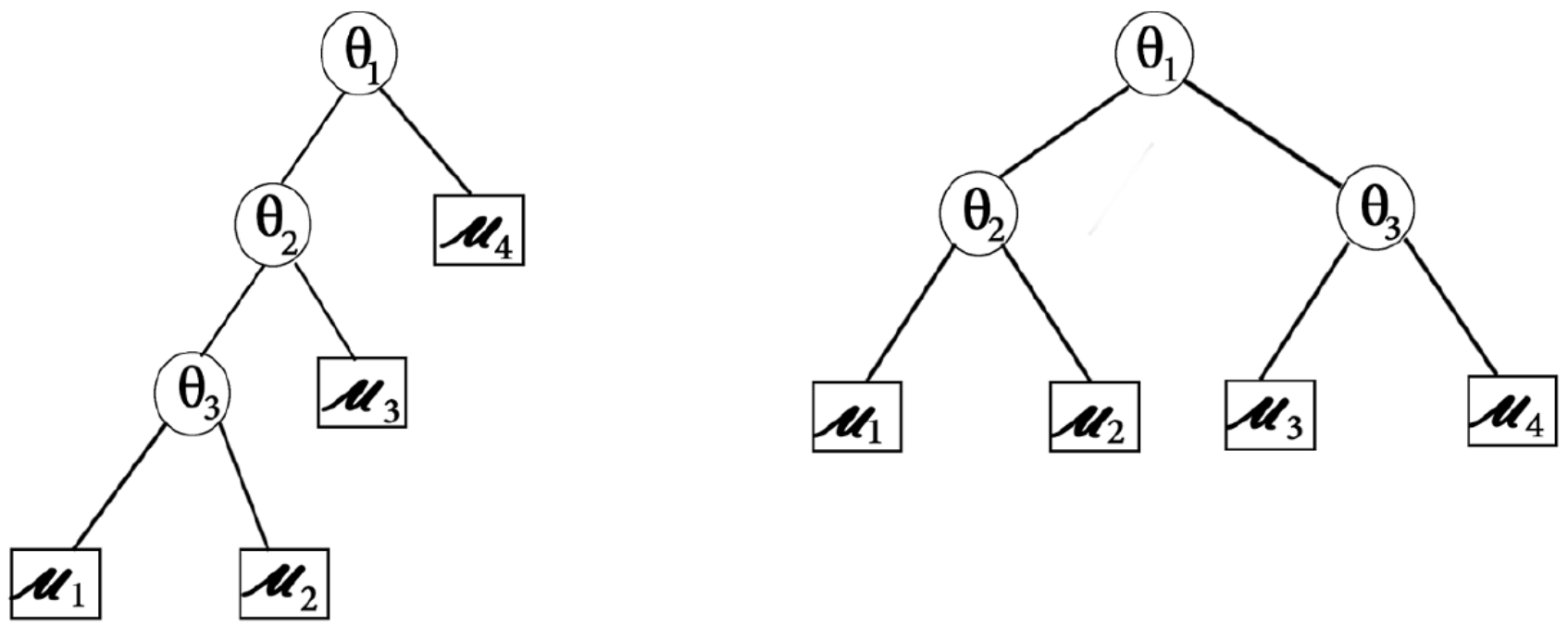

Figure 1: Fully and partially Nested Archimedean copula of dimension $d=4$ with structures $\mathrm{s}=(((12) 3) 4)$ of the left and $\mathrm{s}=((43)(12))$ on the right.

As displayed in Figure 1, this form is called fully nested HAC. The composition can be applied recursively using different segmentation of variables leading to more complex HACs. For notational convenience, we denote the structure of a HAC by:

$$
s=\left\{\left(\ldots\left(i_{1} \ldots i_{j 1}\right) \ldots(\ldots) \ldots\right)\right\}
$$

where: $i_{l} \in 1, \ldots, d$ Is a reordering of the indexes of the variables and $s_{j}$ denotes the structure of sub-copula with $s_{d}=s$.

Let the d-dimensional HAC be denoted by $C\left(u_{1}, \ldots, u_{d} ; s ; \theta\right)$ where $\theta$ denotes the vector of feasible dependency parameters. Thus, the Fully Nested Archimedean Copula can be expressed as:

$$
\begin{gathered}
\left.C\left(u_{1}, \ldots, u_{d} ; s\right)=(((12) 3) 4), \theta\right)=C\left\{u_{1}, \ldots, u_{4} ;\left(\left(s_{3}\right) 4\right) ;\left(\theta_{1}, \theta_{2}\right)^{T}\right\} \\
C\left(u_{1}, \ldots, u_{d} ; s\right)=\varphi_{\theta_{3}}\left(\varphi_{3}^{-1} \circ C\left\{u_{1}, \ldots, u_{3} ;\left(\left(s_{2}\right)(3)\right) ;\left(\theta_{1}, \theta_{2}\right)^{T}\right\}+\varphi_{\theta_{3}}^{-1}\left(u_{4}\right)\right)
\end{gathered}
$$

HACs can adopt arbitrary elaborate structures. This makes it a very flexible and simultaneously parsimonious distribution model. The generators $\varphi_{\theta_{i}}$ within a HAC can come either from a single generator family or from different generator families. If the $\varphi_{\theta_{i}}$ 's belong to the same family, then the required complete monotonicity of $\varphi_{\theta_{i+1}}^{-1} \circ \theta_{i}$ usually imposes some constraints on the parameters $\theta_{1}, \ldots, \theta_{d-1}$.

\section{Estimation}

The natural approach to estimating hierarchical Archimedean copulas is by maximum likelihood if the margins are known (up to a vector of parameters), and canonical maximum likelihood method if the margins are estimated non parametrically by their empirical distribution function. In the following, we will restrict ourselves to the canonical maximum likelihood method. The density 
$c_{L, 1}(u)$ of the hierarchical copula depends on the unknown parameter vector $\theta$ with elements $\theta_{l, j}$ for $l=1, \ldots, L$ and $j=1, \ldots, n_{l}$. Of course, the number of elements of $\theta$ corresponds to the number of generators used to construct the hierarchical copula. Let $\left(U_{11}, \ldots, U_{d 1}\right), \ldots,\left(U_{1 T}, \ldots, U_{d T}\right)$ be a random sample of size $T$ from the d-dimensional random vector $\left(U_{1}, \ldots, U_{d}\right)$. The (canonical) log-likelihood function is:

$$
\ln L\left(\theta ; u_{i t}, i=1, \ldots, d, t=1, \ldots, T\right)=\sum_{t=1}^{T} \ln C_{L, 1}\left(u_{1 t}, \ldots, u_{d t} ; \theta\right)
$$

and the canonical maximum likelihood estimator of $\theta$ is:

$$
\hat{\theta}=\arg \max \ln L(\theta)
$$




\section{Empirical Analysis}

In this section, we study the dependence structure between oil prices, gold prices, and the USD exchange rates. In the first step, various copula models are fitted to standardized residuals from the marginal models, and their suitability is compared. Then, we introduce our new model which is the Nested Archimedean Copula (HAC) for the overall and crisis period.

Oil prices started rising in the U.S. in early2002 and continued their climb from a low of $\$ 30$ per barrel in 2002 to a high of around $\$ 150$ by mid-2008. The principle reason that Americans ignored the earlier price increase would seem to be because they could afford to do so. However, as the financial crisis of 2007 - 09 increased uncertainty and pushed the economy into a recession in December 2007, Americans decreased their demand for oil and oil prices crashed. From a high price of $\$ 150$ per barrel of oil in mid-2008, the price crashed back to around $\$ 30$ by the end of 2008 .

Although gasoline prices were likely a key factor behind plunging sales for U.S. automakers in the first half of 2008, falling income appear to be the biggest factor. While oil is a commodity that plays a critical role in the global economy, the price of both gold and the Euro had very similar price patterns to oil.

For example, since the early introduction of the Euro in 1999 (and notes and coins in 2002), it initially weakened against the dollar, and subsequently, it strengthened with very high correlation with the price of oil during the 2005 - 2007 period. Similarly, gold prices have been moving in the direction similar to oil. The sub-prime crisis is a crisis affecting the U.S. mortgage industry and who contributed to the outbreak of the financial crisis of 2007 to 2009.

To our best knowledge, this is the first application of the HAC dealing with oil, gold, and USD exchange rates for the normal and the troubled period. Notice the Student- $t$ copula is an elliptic, nonArchimedean bivariate copula. The hierarchical copula is a multivariate Archimedean-type copula. In the multivariate framework, the Student- $t$ copula is not part of the HAC (Hierarchical Archimedean Copulas). Therefore, it does not stand out as the most suitable copula (as found in the bivariate framework).

Eventually, for portfolio construction, a BiVaR will be employed in order to examine the comovement of our variables.

\subsection{Data}

In this paper, we use daily crude oil prices, gold prices and five U.S.Dollar (USD) nominal exchange rates over the period from January 3, 2000, to December 21, 2017. As our objective is to examine the relationship between oil, gold, and foreign exchange markets from the perspective of current market trading activities, nominal data on oil, gold, and exchange rates are sufficient. FX series are denominated in dollars per unit of foreign currency.

Gold is priced in the US Dollar per troy ounce. Exchange rates correspond to the amount of USD per one unit of each of five major currencies in international trade: the Euro (EUR), the Canadian Dollar(CAD), the British Pound Sterling (GBP), the Swiss Franc (CHF) and the Japanese Yen (JPY). An increase in the nominal exchange rates considered thus reflects depreciation of the USD relative to foreign currencies.

As to oil prices, we employ two of the most important benchmarks in crude oil pricing: the West Texas Intermediate (WTI) crude at Coshing and the Brent crude from the North Sea. The Brent index serves as the pricing benchmark for two-thirds of the world's internationally traded crude oil supplies. ${ }^{1}$

\footnotetext{
${ }^{1}$ The USD exchange rates are downloaded from the Board of Governors of the Federal Reserve System. WTI and Brent prices are downloaded from the website of US Energy Information Agency:(http//www.eia.doe.gov). Gold prices are from OECD, World Gold Council.
} 
Table 1: Descriptive statistics

\begin{tabular}{|c|c|c|c|c|c|c|c|c|}
\hline & Euro & CHF & JPY & GBP & CAD & Gold & WTI & Brent \\
\hline Max & 0.0462 & 0.1310 & 4.6100 & 4.1033 & 0.0490 & 2.3026 & 0.1641 & 0.1813 \\
\hline Min & -0.0359 & -0.1302 & -4.5980 & -4.0928 & -0.0566 & -2.3285 & -0.1709 & -0.1989 \\
\hline Mean(\%) & $3.2299 \mathrm{e}-05$ & $-1.0380 \mathrm{e}-04$ & $2.2384 \mathrm{e}-05$ & $-2.7760 \mathrm{e}-05$ & $-3.3338 \mathrm{e}-05$ & $3.3664 \mathrm{e}-04$ & $1.7788 \mathrm{e}-04$ & $2.0039 \mathrm{e}-04$ \\
\hline Skewness & 0.0698 & -0.8745 & 0.1609 & 0.1825 & -0.1513 & -0.7561 & 7.4255 & -0.1327 \\
\hline Kurtosis & 5.3874 & 65.6492 & $1.5153 \mathrm{e}+03$ & $2.2246 \mathrm{e}+03$ & 10.9123 & $2.0192 \mathrm{e}+03$ & 7.4255 & 8.2535 \\
\hline Std & 0.0063 & 0.0076 & 0.1088 & 0.0867 & 0.0059 & 0.0502 & 0.0248 & 0.0228 \\
\hline JB & 1 & 1 & 1 & 1 & 1 & 1 & 1 & 1 \\
\hline
\end{tabular}

Kurtosis refers to the degree of the peak in a distribution. In our case, and regarding Table 1, results show that Kurtosis $\succ 3$ for all variables which prove that all distributions are higher than the normal distribution, having the fat tail. It means that the probability of extremely realizations is important.

Skewness can be defined as the averaged cubed deviation from the mean divided by the standard deviation cubed. If the result of the computation is greater than zero, the distribution is positively skewed. If it is less than zero, it is negatively skewed and equal to zero means it is symmetric.

For our returns series, Skewness $\prec 0$ for the CHF, CAD, Gold, and Brent returns series which means that are left-skewed distribution and most values are concentrated on the right of the mean, with extreme values to the left .

For the others variables, the Skewness $\succ 0$ which means that are right-skewed distribution and most values are concentrated on left of the mean, with extreme values to the right.

Economically, fixed prices of oil and gold versus the Dollar exhibit a large kurtosis because their values are kept pegged to each other within a certain range by monetary authorities. When a fixed rate is abandoned to increase the transparency in which the markets operate the fluctuation shown by the currency indicate substantial positive or negative values as compared to the fixed rate period.

Direct statistical analysis of financial prices is difficult because consecutive prices are highly correlated, and the variance of prices often increase with time. This makes it usually more convenient to analyze changes in prices.

Figure 2 illustrates this case which shows consecutive daily prices of WTI covering the period January 3, 2000, to December 21, 2017.

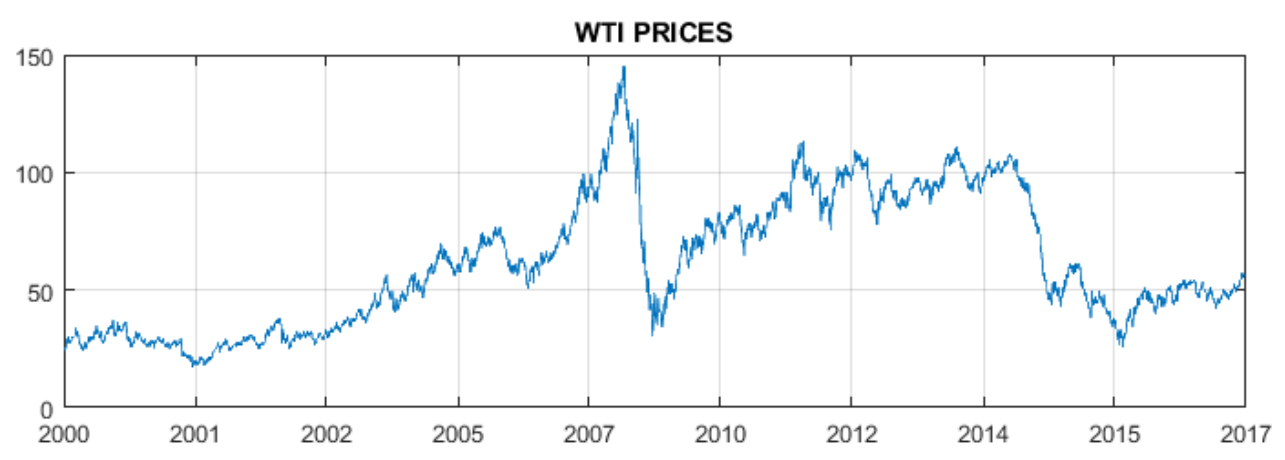

Figure 2: Daily spot prices of crude oil.

Financial time series usually exhibit a characteristic known as volatility clustering, in which large changes tend to follow large changes, and small changes tend to follow small changes.

In either case, the changes from one period to the next are typical of an unpredictable sign. Volatility clustering, or persistence, suggests a time series model in which successive disturbances, although uncorrelated, are nonetheless serially dependent.

We compute then, the returns on crude oil prices, gold prices, and the USD exchange rates by taking the difference in the logarithm of the two successive daily prices. 
As we can see in Figure 3, that daily returns were fairly stable during the period preceding the start of the global financial crisis(January 2000 to the third quarter of 2008), sparked by the massive failures in the U.S subprime mortgage and banking sectors. After that, all returning series exhibited higher instability.
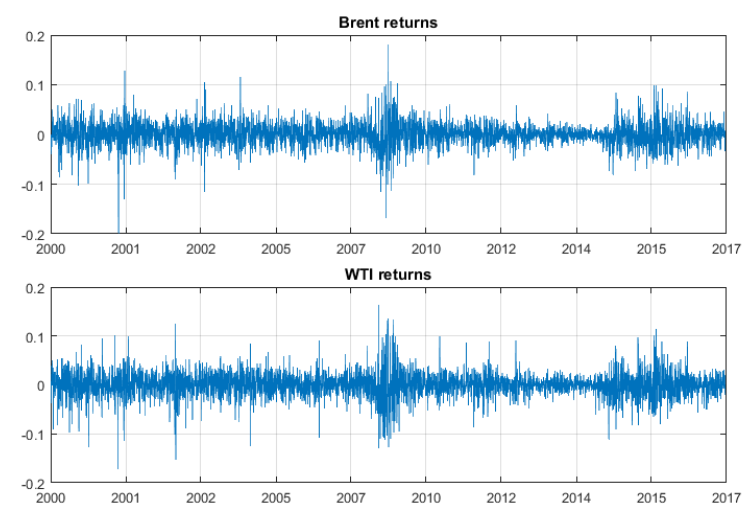

Figure 3: Daily returns on crude oil WTI and Brent.

Table 2: Statistical properties of return series

\begin{tabular}{|c|c|c|c|c|c|c|c|c|}
\hline & CHF & EUR & JPY & GBP & CAD & GOLD & WTI & BRENT \\
\hline$Q(15)$ & $75.31^{* *}$ & 15.55 & $22.33^{* *}$ & $56.78^{* *}$ & 19.89 & $34.18^{* *}$ & $35.01^{* *}$ & $26.80^{* *}$ \\
\hline$Q^{2}(15)$ & $29.94^{* *}$ & $624.26^{* *}$ & $22.54^{* *}$ & $612.21^{* *}$ & $25.87^{* *}$ & $998.81^{* *}$ & $33.74^{* *}$ & $699.36^{* *}$ \\
\hline JB & $32151^{* *}$ & $609.65^{* *}$ & $666.93^{* *}$ & $4575^{* *}$ & $3343.8^{* *}$ & $2699.1^{* *}$ & $1511.6^{* *}$ & $1934.4^{* *}$ \\
\hline$A R C H(15)$ & $23.17^{* *}$ & $307.20^{* *}$ & $42.13^{* *}$ & $316.82^{* *}$ & $509.18^{* *}$ & $405.43^{* *}$ & $556^{* *}$ & $316.56^{* *}$ \\
\hline
\end{tabular}

The Ljung-Box Q-statistics of order 15 shows the existence of autocorrelation in all the return series, except for the EUR and CAD series. The Ljung-Box statistics of order 15 applied to squared returns are highly significant. Results of the Lagrange Multiplier tests point to the presence of ARCH effects in the return data, thus supporting our decision to use the GARCH-based approach. ${ }^{2}$

\subsubsection{Marginal model results}

Before the copula functions can be used to measure the degree of interdependence among variables. We must choose the most appropriate specifications for modeling the conditional heteroscedasticity and for filtering the negative log returns into an approximately iid series. The GARCH sophisticated extensions were firstly introduced by Bollerslev (1986) is the most commonly used financial time series models. Hereafter, we estimate two GARCH extension models, that is, GJR-GARCH and EGARCH models. In order to choose the appropriate model, we use the four criteria: Log-likelihood, Akaike criterion (AIC), Schwarz criterion and Hannan-Quinn criterion. Therefore, the best model according to our four criteria is the GJR-GARCH. ${ }^{3}$

\footnotetext{
${ }^{2}$ Table 2 displays the statistics $Q(15)$ and $Q^{2}(15)$ which are the Ljung-Box statistics for serial correlation of order 15 in returns and squared returns. ARCH is the Lagrange Multiplier test for autoregressive conditional heteroscedasticity. * and $* *$ indicate the rejection of the null hypothesis of no autocorrelation, normality, and homoscedasticity at the $1 \%$ and $5 \%$ levels of significance respectively.

${ }^{3}$ Tables $3 \mathrm{a}$ and $3 \mathrm{~b}$ generate different criteria for select the best model between GJR-GARCH and EGARCH.
} 
Table 3a:GJR GARCH

\begin{tabular}{|l|c|c|c|c|c|c|c|c|}
\hline & Euro & CHF & JPY & GBP & CAD & Gold & WTI & Brent \\
\hline $\log$ & 16725.106 & 16367.863 & 16437.794 & 17114.618 & 17360.890 & 14417.749 & 10894.866 & 11219.453 \\
\hline SC & -7.4337 & -7.2747 & -7.3058 & -7.6071 & -7.7166 & -6.4066 & -4.8347 & -4.9792 \\
\hline HQ & -7.4393 & -7.2803 & -7.3114 & -7.6127 & -7.7222 & -6.4122 & -4.8421 & -4.9866 \\
\hline AIC & -7.4423 & -7.2833 & -7.3144 & -7.6157 & -7.7252 & -6.4152 & -4.8461 & -4.9906 \\
\hline
\end{tabular}

Table 3b:EGARCH

\begin{tabular}{|l|c|c|c|c|c|c|c|c|}
\hline & Euro & CHF & JPY & GBP & CAD & Gold & WTI & Brent \\
\hline log & 16552.467 & 16219.369 & 16351.263 & 16938.5 & 17159.768 & 14291.4 & 10794.091 & 11093.920 \\
\hline SC & -7.3531 & -7.2048 & -7.2635 & -7.5249 & -7.6234 & -6.3466 & -4.7898 & -4.9233 \\
\hline HQ & -7.360 & -7.212 & -7.270 & -7.532 & -7.630 & -6.354 & -4.797 & -4.930 \\
\hline AIC & -7.364 & -7.216 & -7.274 & -7.536 & -7.634 & -6.358 & -4.801 & -4.934 \\
\hline
\end{tabular}

Table 4:Parameter estimates for marginal models ${ }^{4}$

\begin{tabular}{|l|c|c|c|c|c|c|c|c|}
\hline & Euro & CHF & JPY & GBP & CAD & Gold & WTI & Brent \\
\hline Mean & Equation & & & & & & & \\
\hline \hline Constant $\left(10^{4}\right)$ & 0.0000827 & -0.0000418 & 0.000104 & 0.0000677 & -0.0000166 & 0.000360 & 0.000579 & 0.000334 \\
\hline AR $(1)$ & -0.008608 & -0.030798 & -0.017130 & 0.012543 & 0.002606 & -0.040537 & -0.033777 & 0.017050 \\
\hline Variance & Equation & & & & & & & \\
\hline \hline$\omega\left(10^{6}\right)$ & 0.066691 & 0.396585 & 0.427733 & 0.223946 & 0.126686 & 0.013744 & 0.022150 & 0.007360 \\
\hline$\alpha\left(10^{2}\right)$ & 0.025312 & 0.035145 & 0.096555 & 0.030920 & 0.044314 & 0.079299 & 0.023934 & 0.015274 \\
\hline$\beta$ & 0.968034 & 0.953471 & -0.000342 & 0.954387 & 0.958040 & 0.933732 & 0.953282 & 0.966188 \\
\hline$\gamma$ & 0.011444 & 0.005913 & 0.046510 & 0.015872 & -0.045710 & -0.0454710 & 0.037845 & 0.035444 \\
\hline$v$ & 7.572895 & 5.812659 & 3.749222 & 8.301206 & 7.130939 & 5.412206 & 6.362070 & 6.468287 \\
\hline
\end{tabular}

\subsubsection{Copula model results}

Table 5 :Estimates of the dependence parameters of different copula models. ${ }^{5}$

\begin{tabular}{|l|r|rc|r|r|r|}
\hline & Normal & Student-t & & Gumbel & Clayton & Frank \\
\hline & $\rho$ & $\rho$ & $\nu$ & $\theta$ & $\theta$ & $\theta$ \\
\hline CHF-WTI & 0.1073 & 0.1431 & 14.54 & 1.0867 & 0.1417 & 0.8601 \\
\hline EUR-WTI & 0.1566 & 0.1615 & 11.6294 & 1.0998 & 0.1739 & 0.9709 \\
\hline JPY-WTI & -0.0336 & 0.0359 & 10.9375 & 1.0233 & 0.0495 & -0.2136 \\
\hline GBP-WTI & 0.0012 & 0.0018 & 67.0280 & 1.0000 & 0.0030 & 0.0440 \\
\hline CAD-WTI & 0.0179 & 0.0181 & 31.7099 & 1.0132 & 0.0142 & 0.1083 \\
\hline CHF-Brent & 0.1763 & 0.1764 & 13.71 & 0.1893 & 1.1117 & 1.0263 \\
\hline EUR-Brent & 0.2151 & 0.2147 & 12.97 & 1.0000 & 0.0167 & 0.0063 \\
\hline JPY-Brent & -0.0009 & -0.0008 & 82.5625 & 1.0000 & 0.0140 & -0.0124 \\
\hline GBP-Brent & 0.1932 & 0.1920 & 20.30 & 0.2020 & 1.1184 & 1.1020 \\
\hline CAD-Brent & 0.0204 & 0.0203 & 43.5888 & 1.0107 & 0.0210 & 0.0919 \\
\hline CHF-Gold & -0.2273 & -0.2266 & 15.6516 & 1.0000 & 0.0035 & -1.3137 \\
\hline EUR-Gold & -0.2286 & -0.2293 & 15.9137 & 1.1477 & 0.2534 & -1.3580 \\
\hline JPY-Gold & -0.1476 & -0.1452 & 12.2984 & 1.0000 & 0.0035 & -0.8224 \\
\hline GBP-Gold & -0.3100 & -0.3202 & 9.30 & 1.2309 & 0.3838 & -1.0077 \\
\hline CAD-Gold & -0.0229 & -0.0230 & 1061.53 & 1.0000 & 0.0035 & -0.1329 \\
\hline WTI-Gold & 0.1859 & 0.1885 & 22.60 & 0.2333 & 1.0492 & 1.0882 \\
\hline BRENT-Gold & 0.2242 & 0.2162 & 22.55 & 0.2302 & 1.5925 & 1.1429 \\
\hline
\end{tabular}

\footnotetext{
${ }^{4}$ Table 4 reports ML parameter estimates for the eight variables of the AR(1)-GJR-GARCH(1,1) models. More details are in Appendices.

${ }^{5}$ Table 5 present the parameters estimation of different copula: Elliptical and Archimedean copula
} 
Let us inspect the results obtained in Table 5 about pairs dependence. First, the low dependence with the USD/CAD appears logical. The biggest countries in global oil production exhibit the lowest dependence between foreign exchange and oil market volatilities. Similar evidence is provided by Aloui et al. (2013). Canada is one of the largest producers of crude oil, while the Euro-zone is net-oil importer with a relatively low domestic production compared to the top world oil producers. Accordingly, foreign exchange and crude oil markets are more likely to be interlinked for European countries.

Concerning the results for the USD/JPY, the lack of dependence (i.e., negative with WTI and Brent crude oil) between both markets is more surprising, as Japan is highly dependent on energy imports and more particularly on crude oil (recall that Japan is the third largest oil importer). Different factors could explain this finding. First, this country experienced a significant decrease in oil consumption since 2005 (given the rapid growth of the oil price). Second, the Japanese authorities committed to reducing their oil share in key industrial sectors in favor of alternative energy sources. A third reason is that crude oil imports from Japan originate mostly from OPEC countries.

The relationship between gold and the US dollar seems to be awkward at the beginning, in so far as gold is priced in this currency. Would it not be impossible to settle on such a relationship? Otherwise, the relationship between gold and currency can be associated with the foreign exchange rate of that currency. In our case, the negative and weaker dependence between the currencies and gold (except for the GBP) imply that the currencies mostly deviated from their real value especially in the crisis period. In general, we found that fluctuations in the global price of gold are not correlated with fluctuations in any individual currency. It, therefore, appears that gold is not a hedge against the external purchasing power for any individual currency. This finding implies that the global price of gold should not be used for hedging individual currency risk.

In 2008, the IMF estimated that 40-50\% of moves in the gold price since 2002 were dollar-related. A $1 \%$ change in the effective external value of the US dollar leads to more than a $1 \%$ change in the gold price. First, a falling dollar increases the value of other local currencies, which increases the demand for commodities including gold. Second, when the USD starts losing its value compared to its trading partners, investors look for alternative investment sources to store value, which is gold. However, it is important to realize that its possible for the USD and gold price to increase at the same time. This can occur in the presence of a crisis in some other countries or regions. This would cause investors to flee to safer assets, different from USD and gold. The USD is also driven by other factors like monetary policy and inflation and economic prospects in the USA vs. other countries. Investors and portfolio managers need to consider all of these factors as well as historical facts.

Our results are consistent with the findings of Wang and Chueh (2013), who identified the positive interaction between gold and oil prices for the period 1989-2007. One possible argument states that the rising oil price is bad for the economy, dampening growth and dropping stock prices, so investors look for alternative assets such as gold. Thus, the oil price indirectly affects the price of gold. Indeed, both oil and gold trades are invoiced in USD. Therefore, their pricing process depends on the strength of that currency, as driven by its inflation rate. It can also be argued that sharing similar characteristics does not imply interactions per se. It could also be because their prices are driven by a common factor: the US inflation rate.

\subsubsection{Copula choice: Goodness-of-fit Test of Genest et al. (2009):}

In order to check the overall quality of the fit, we use the goodness-of-fit test of Genest an al. (2009), which is based on a comparison of the distance between the estimated and the empirical copula:

$\mathbb{C}_{n}=\sqrt{n}\left(C_{n}-C_{\theta_{n}}\right)$

The test statistics considered is based on Cramer-Von Mises distance defined as:

$S_{n}=\int \mathbb{C}(u)^{2} d C_{n}(u)$

Large values of the statistic $S_{n}$ lead to the rejection of the null hypothesis that the copula $C$ belongs to a class $C_{0}$. 
In practice, we require knowledge about the limiting distribution of $S_{n}$ which depends on the unknown parameter value $\theta$. To find the $p$-values associated with the test statistics we use a multiplier approach as described in Kojadinovic and Yan (2011).

The higher the $p$-value, the smaller the distance between the estimated and empirical copula. Hence, the copula in use provides the best fit to the data. In our case, and with reference to results in Table 6, results of the test of Genest et al. (2009) the Student- $t$ copula is selected. Indeed, the Student- $t$ copula show the highest $p$-value. It is pictured in Figure 4.

Table 6: $p$-value of the Goodness-of-fit test of Genest et al. (2009).

\begin{tabular}{|l|c|c|c|c|c|}
\hline & Normal & Student-t & Gumbel & Clayton & Frank \\
\hline CHF-WTI & 0.546 & 0.7378 & 0.002 & 0.0004 & 0.536 \\
\hline EUR-WTI & 0.055 & 0.2882 & 0.0004 & 0.0004 & 0.0094 \\
\hline JPY-WTI & 0.1553 & 0.8876 & 0.2393 & 0.3022 & 0.1284 \\
\hline GBP-WTI & 0.4461 & 0.496 & 0.002 & 0.5819 & 0.654 \\
\hline CAD-WTI & 0.7248 & 0.9040 & 0.9376 & 0.533 & 0.6299 \\
\hline CHF-Brent & 0.7597 & 0.7567 & 0.002 & 0.7857 & 0.7178 \\
\hline EUR-Brent & 0.3432 & 0.3472 & 0.002 & 0.3102 & 0.2662 \\
\hline JPY-Brent & 0.3002 & 0.3232 & 0.002 & 0.2313 & 0.2273 \\
\hline GBP-Brent & 0.9995 & 0.9985 & 0.0003 & 0.995 & 0.9985 \\
\hline CAD-Brent & 0.1244 & 0.1314 & 0.002 & 0.2213 & 0.0744 \\
\hline CHF-Gold & 0.0974 & 0.2293 & 0.002 & 0.0004 & 0.0004 \\
\hline EUR-Gold & 0.7667 & 0.7208 & 0.0004 & 0.0004 & 0.028 \\
\hline JPY-Gold & 0.2912 & 0.2083 & 0.002 & 0.0004 & 0.0004 \\
\hline GBP-Gold & 0.9985 & 0.534 & 0.003 & 0.063 & 0.3541 \\
\hline CAD-Gold & 0.1324 & 0.9815 & 0.002 & 0.062 & 0.975 \\
\hline WTI-Gold & 0.0074 & 0.0094 & 0.0004 & 0.0004 & 0.0594 \\
\hline BRENT-Gold & 0.9056 & 0.9376 & 0.002 & 0.0004 & 0.9206 \\
\hline
\end{tabular}



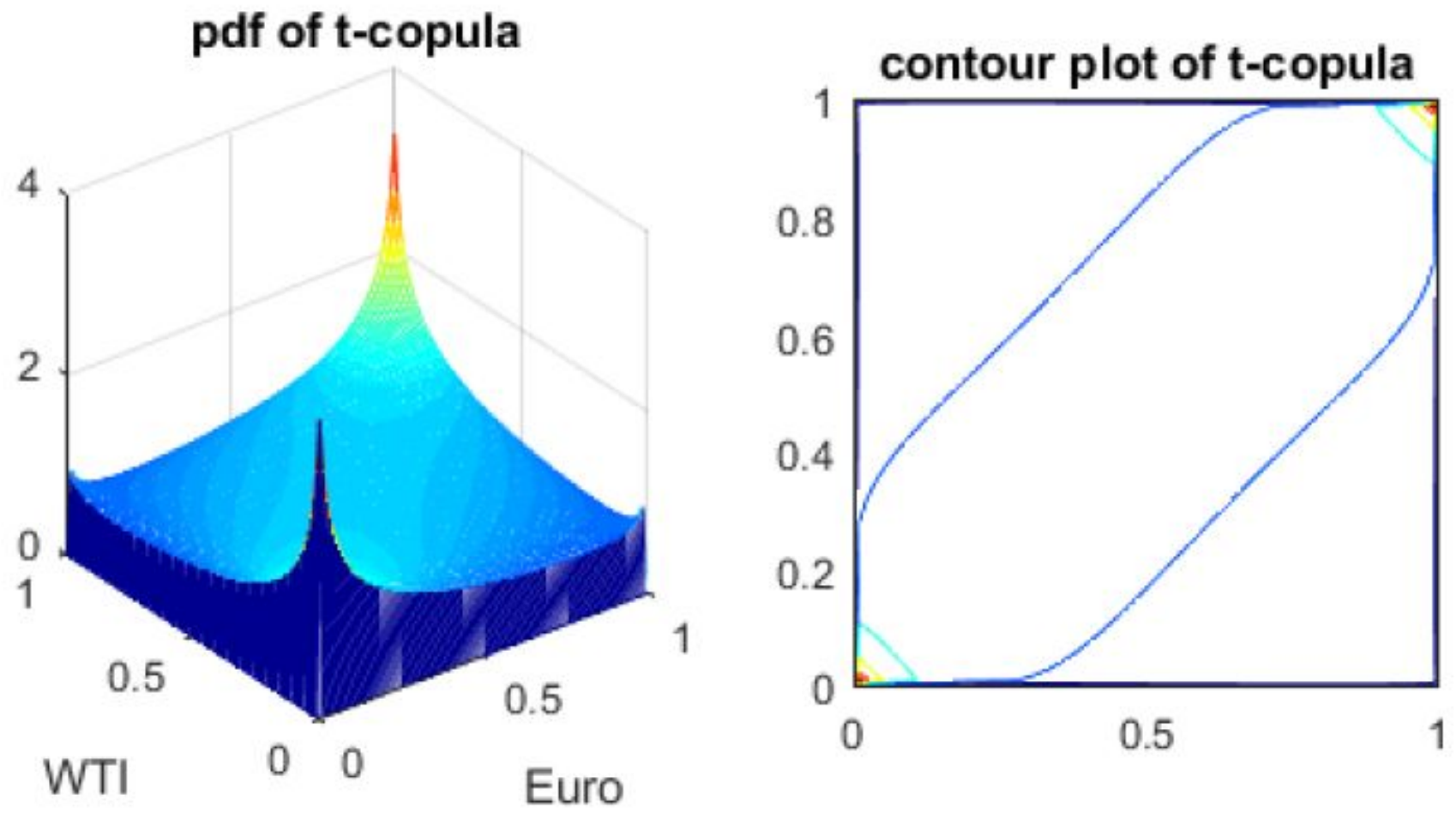

Figure 4: Density of the selected copula.

\subsection{Multivariate dependence and crisis impact: Nested copula during two sub-periods}

Sifneos (1960) has identified four components of an emotional crisis:

1. The hazardous event that starts the chain of reactions that lead to the crisis. Sometimes it is a sudden unexpected event, while other times it can be a developmental change.

2. A vulnerable state of the individual which is essential for the crisis to develop.

3. The precipitating factor that is the final event or circumstance that makes the hazardous event unbearable and results in the crisis

4. The state of ongoing crisis.

An essential characteristic of crisis reactions is that they are time limited. During the crisis the individual experiences an increased desire to be helped by others and is more open and amenable to outside intervention than at times of stable functioning (CAPLAN, 1964).

Oil prices started rising in the U.S. in early 2002 and continued their climb from a low of $\$ 30$ per barrel in 2002 to a high of around $\$ 150$ by mid-2008. The principle reason that Americans ignored the earlier price increase would seem to be because they could afford to do so. However, as the financial crisis of 2007-09 increased uncertainty and pushed the economy into a recession in December 2007, Americans decreased their demand for oil and oil prices crashed. From a high price of $\$ 150$ per barrel of oil in mid-2008, the price crashed back to around $\$ 30$ by the end of 2008. Although gasoline prices were likely a key factor behind plunging sales for U.S. automakers in the first half of 2008, falling income appear to be the most significant factor.

While oil is a commodity that plays a critical role in the global economy, the price of both gold and the Euro had very similar price patterns to oil. For example, since the early introduction of the Euro in 1999 (and notes and coins in 2002), it initially weakened against the dollar, and subsequently, it strengthened with very high correlation with the price of oil during the $2005-2007$ period. Similarly, 
gold prices have been moving in the direction similar to oil. Our troubled period begin from July 16, 2007, to December, 30,2011.

Table 7 : Multistage estimation procedure for Oil,Gold and USD exchange rates.

\begin{tabular}{|l|c|c|c|c|}
\hline Structure & Gumbel & Clayton & Frank & Joe \\
\hline Overall Period & & & & \\
\hline (WTI Gold) & 6.95 & 5.7 & 26.32 & 9.81 \\
\hline ((WTI Gold)CHF $)$ & 6.28 & 4.63 & 22.28 & 8.3 \\
\hline (((WTI Gold)CHF)EUR) & 5.23 & 3.75 & 18.62 & 6.48 \\
\hline (((((WTI Gold)CHF)EUR)JPY) & 3.98 & 3.14 & 14.22 & 5.37 \\
\hline ((((((WTI Gold)CHF)EUR)JPY)GBP) & 2.88 & 2.22 & 10.34 & 3.83 \\
\hline (((((WTI Gold)CHF)EUR)JPY)GBP)CAD) & 1.91 & 1.15 & 5.81 & 2.48 \\
\hline (BRENT Gold) & 7.14 & 4.98 & 25.13 & 9.9 \\
\hline ((BRENT Gold)CHF) & 6.12 & 4.74 & 20.85 & 8.23 \\
\hline (((BRENT Gold)CHF)EUR) & 5.09 & 3.65 & 17.94 & 6.8 \\
\hline (((BRENT Gold)CHF)EUR)JPY) & 4.03 & 3.03 & 13.88 & 5.43 \\
\hline (((((BRENT Gold)CHF)EUR)JPY)GBP) & 3.03 & 2.33 & 9.76 & 3.92 \\
\hline ((((((BRENT Gold)CHF)EUR)JPY)GBP)CAD) $)$ & 2.02 & 1.28 & 5.96 & 2.42 \\
\hline
\end{tabular}

Table 8: Multistage estimation procedure for Oil,Gold and USD exchange rates.

\begin{tabular}{|l|c|c|c|c|}
\hline Structure & Gumbel & Clayton & Frank & Joe \\
\hline Crisis Period & & & & \\
\hline (WTI Gold) & 6.91 & 5.56 & 24.84 & 9.94 \\
\hline ((WTI Gold)CHF) & 6.26 & 5.22 & 20.73 & 8.45 \\
\hline (((WTI Gold)CHF)EUR) & 5.12 & 4.1 & 17.39 & 6.98 \\
\hline (((((WTI Gold)CHF)EUR)JPY) & 3.94 & 3.05 & 14 & 5.25 \\
\hline ((((((WTI Gold)CHF)EUR)JPY)GBP) & 2.91 & 2.08 & 9.45 & 3.76 \\
\hline ((((((WTI Gold)CHF)EUR)JPY)GBP)CAD) & 1.93 & 1.44 & 5.83 & 2.45 \\
\hline (BRENT Gold) & 7.12 & 6.15 & 24.76 & 10.09 \\
\hline ((BRENT Gold)CHF) & 6.04 & 5.18 & 22.53 & 8.26 \\
\hline (((BRENT Gold)CHF)EUR) & 5.23 & 4.2 & 18.65 & 6.43 \\
\hline (((BRENT Gold)CHF)EUR)JPY) & 4.02 & 3.03 & 13.94 & 5.08 \\
\hline (((((BRENT Gold)CHF)EUR)JPY)GBP) & 2.92 & 2.08 & 10.17 & 3.94 \\
\hline ((((((BRENT Gold)CHF)EUR)JPY)GBP)CAD) $)$ & 1.98 & 1.25 & 5.88 & 2.32 \\
\hline
\end{tabular}

Gleaning information from Tables 7 and 8, the multistage estimation for the Nested copula during normal and crisis period shows that the dependence among variables becomes stronger in the crisis period captured by Frank and the Joe copula.

This finding provides a key implication that financial crisis did accelerate the dependence among returns of Oil, Gold, and USD exchange rates which altered the effects of USD exchange rates in both Gold and Oil. They provide evidence of both contagion and interdependence. This empirical evidence has important implications for monetary and fiscal policies, asset management and risk assessment.

Economically, the financial crisis is often associated with significant movements in exchange rates, which reflect both increasing risk aversion and changes in the perceived risk of investing in certain currencies and precious metals. Thus, the global financial crisis of 2008 was no exception.

Exchange rate movements during the global financial crisis of 2007-2009 were unusual. Unlike in two previous episodes - the Asian crisis of 1997-1998 and the crisis following the Russian debt default in 1998, in 2008 a large number of currencies depreciated sharply even though they were not at the center of the crisis. Moreover, in 2009, the crisis-related movements reversed strongly for some countries. With these results, gold and oil are not a better alternative for the investor especially 
during crisis time.

Indeed, policy makers, traders, and investors are all trying to sort out the depth and duration of the coming recession, but the impact on the energy industry is immediately obvious. Oil prices have dropped by over two-thirds since their peak in July 2008. With lower economic activity comes less demand for oil, and although the difference is not great, it is sufficient to reverse the market completely.

Table 9: Results of the Goodness-of-fit test for Hierarchical Archimedean Copulas.

\begin{tabular}{|c|c|c|c|c|}
\hline Structure & Gumbel & Clayton & Frank & Joe \\
\hline \multicolumn{5}{|l|}{ Overall Period } \\
\hline ((((((WTI Gold)CHF)EUR)JPY)GBP)CAD) & 0.9336 & 0.519 & 0.6019 & 0.425 \\
\hline$((((($ BRENT Gold $)$ CHF $)$ EUR $)$ JPY $)$ GBP $)$ CAD $)$ & 0.3302 & 0.1983 & 0.07243 & 0.003 \\
\hline \multicolumn{5}{|l|}{ Crisis Period } \\
\hline ((((((WTI Gold)CHF)EUR)JPY)GBP)CAD) & 0.1483 & 0.09141 & 0.03347 & 0.11 \\
\hline ((((((BRENT Gold)CHF)EUR)JPY)GBP)CAD $)$ & 0.1274 & 0.1424 & 0.04046 & 0.09 \\
\hline
\end{tabular}

In Table 9, the Goodness-of-fit results show that for the overall period Gumbel copula provide the best description of the return dependence of the structure (((((WTI Gold)CHF)EUR)JPY)GBP)CAD) and also captured the best fit for the structure (((((BRENT Gold)CHF)EUR)JPY)GBP)CAD). For the crisis period, Gumbel and Clayton copula is selected .

As illustrated in Figure 5, this difference in results during the sub-periods is naturally, due to the difference in the statistic properties of the return data.

\section{Diagonal densities of Gumbel}

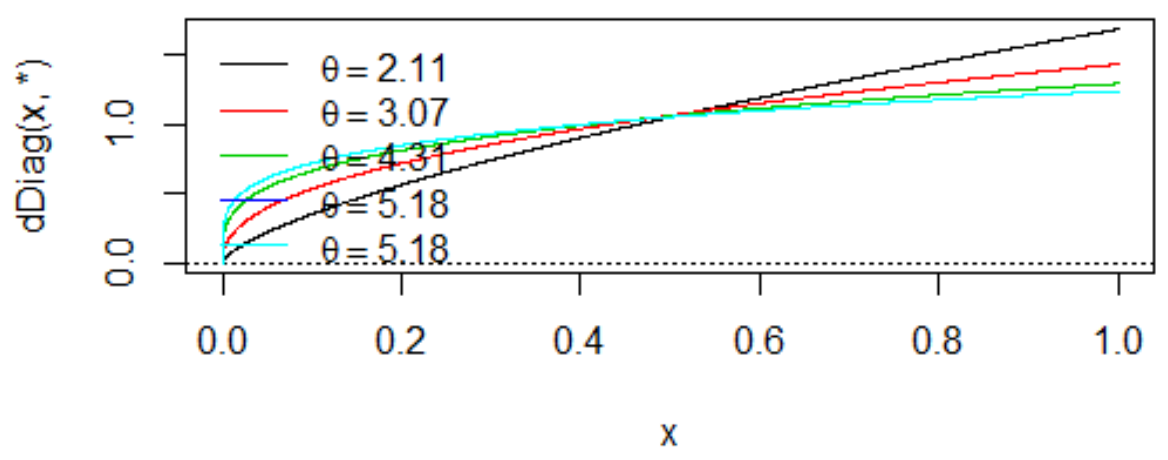

Figure 5: Diagonal density of the selected copula(Gumbel).

\subsection{Bivariate VaR}

The use of copulas allows us to draw the "level curves" of the two-dimensional Value at Risk and examine for a given threshold level, the marginal rate of substitution (TMS) between the VAR of the two univariate risks.

For a given marginal distributions of Oil, Gold and USD exchange returns, it is possible to draw the contours corresponding to the minimum copula (anti-monotonicity), maximum (co-monotonicity) and the copula of independence.

Let $r_{A}$ and $r_{B}$ the returns of the series $\mathrm{A}$ and $\mathrm{B}$. We note $F_{A}$ and $F_{B}$ the univariate distribution functions of returns. Then, we can write, for a threshold $\in[0,1]$ :

$$
\left\{\left(r_{A} ; r_{B}\right) ; \max \left(F_{A}\left(r_{A}\right)+F_{B}\left(r_{B}\right)-1 ; 0\right)=\alpha\right\}: \text { anti-monotonicity; }
$$




$$
\begin{gathered}
\left\{\left(r_{A} ; r_{B}\right) ; F_{A}\left(r_{A}\right) \cdot F_{B}\left(r_{B}\right)=\alpha\right\}: \text { independence; } \\
\left\{\left(r_{A} ; r_{B}\right) ; \min \left(F_{A}\left(r_{A}\right), F_{B}\left(r_{B}\right)\right)=\alpha\right\} \text { :co-monotonicity; }
\end{gathered}
$$

Empirical contours are obtained from the empirical copula :

$$
\left\{\left(r_{A} ; r_{B}\right) ; C\left(F_{A}\left(r_{A}\right), F_{B}\left(r_{B}\right)\right)=\alpha\right\}
$$

The empirical curves allow illustrating the TMS between the two univariate Value at Risk. The higher the level of the empirical curves (close to the anti-monotonicity), the higher more the dependence between the returns $r_{A}$ and $r_{B}$. Such dependence is negative as a result a compensation effect.

The independence case corresponds to the diversification. (see Cherubini and Luciano [2001]). In this section, we study the curves at the level $95 \%$ of the bivariate Value at Risk of Oil, Gold, and the USD exchange rates.

The level curve of the empirical copula over the sample period is not fixed. First, it comes close to the case of anti-monotonicity which means a negative dependence between losses. Then, it moves to the case of co-monotonicity which corresponds to a positive dependence between USD exchange rates and WTI returns. As a result, a higher correlation between losses. Finally, the level curve of the empirical copula is located behind the case of independence .

This situation is the same for all pairs with a fewer difference as we can see in Figure $6^{6}$. Moreover, this case is also observed with USD exchange rates and Gold returns. Regarding our results, the level curves of empirical copula move through the three phases: anti-monotonicity, co-monotonicity, and independence. This can be explained by the fact that the relationship is not fixed and because our study period includes the crisis period which influences this dependence structure for portfolio construction.

${ }^{6} \mathrm{BiVaR}$ Frontier at level $5 \%$ of the other pairs are in appendices. 

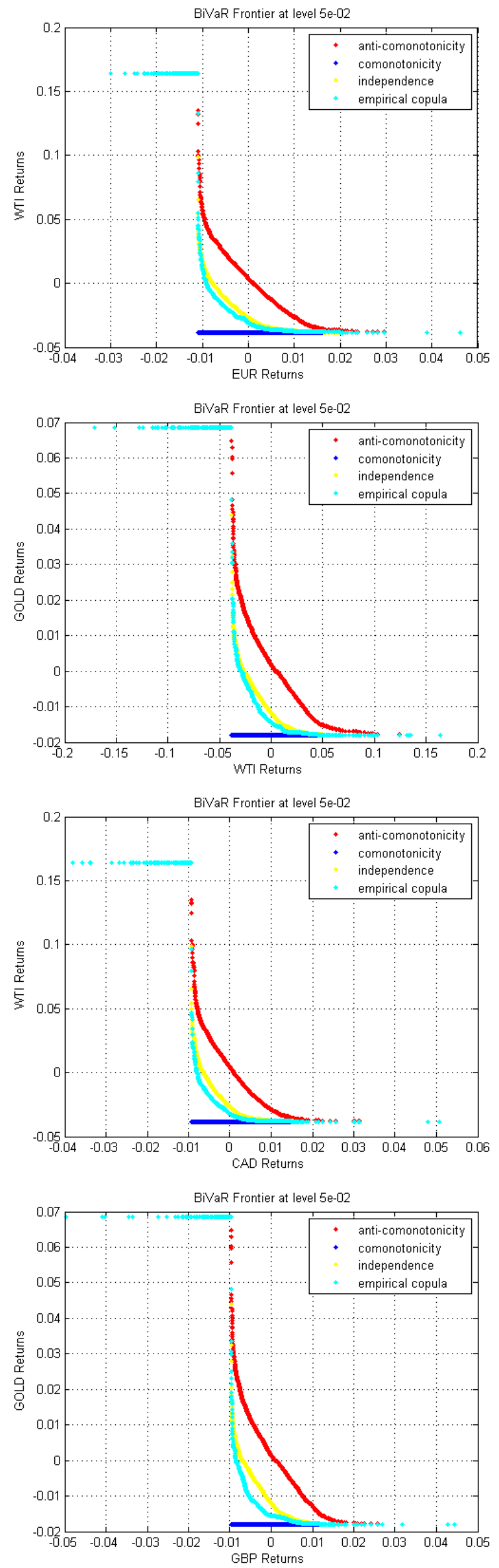

Figure 6: BiVaR Frontier at level 5\% of the Euro, CAD, GBP, Gold, and WTI oil market. 


\section{Discussion}

This article develops a Nested copula-based GJR-GARCH model to investigate the dependence structures of oil, gold and FX markets from January 2000 to February 2018. We also divide the whole period into three sub-periods to compare the difference in the dependence structure between regular and crisis periods.

Empirical results find that the dependence during crisis periods is stronger than that during the untroubled period. All previous researches relating to the dependence structure are conducted using bivariate copula model. Our results obtained with the Nested Archimedean copula are in accordance with the finding of Sari et al. (2010) who proved that oil and gold are positively affected each other.

Moreover, oil remains one of the most important energy sources which highly depend on global economic growth and gold is the most important precious metals. The demand for precious metals as an investment is based on interest rate development and currency fluctuations mainly the US dollars because of the high trade volume in US dollars.

Other interesting findings are identified when analyzing the dependence of oil, gold, and USD exchange rates during the crisis period. During 2009, the crisis-related movement reversed strongly for a large number of countries and with these results gold and oil are not a better alternative for the investor, especially in troubled periods.

Eventually, the article addresses an important issue in the energy commodities and precious metals portfolio construction field. Our research also gives a new insight into the behavior of the dependence structure in the crisis period. However, the dependence of the overall period may mask large variations.

\section{Conclusion}

The energy industry contends with a great amount of uncertainty and risk, and yet companies have to focus on the future to ensure financial and operational success. The oil industry is a diverse and vital part of the global economy. Indeed, it is one of the most important economic activities in the modern world. Either the numbers of business associates or by the politico-military issues, the industry is placed among the most strategic of the world.

Precious metals have a specific value in their durability, relative indestructibility, the fact that they do not oxidize when exposed to the air this physical property make precious metals the natural material for hoarding.

Oil and gold have unique roles in the global economy and are commonly two strategic commodities. They are the most representative commodities field which drives the evolution of the world economy. Since oil and gold are expressed with the USD, a relationship has established. Their dependence has received much attention recently from investors, risk managers and traders.

The focus on this research is to study the impact of the global financial crisis in such relationship, In the first step, we employ the GJR-GARCH process to model the margins. Then, various copula models are fitted to standardized residuals from the marginal models, and their suitability is compared.

Results show that the Student- $t$ copula provides the best fit to the data. Our finding suggests that gold and oil are positively influenced each other, our results are consistent with the finding of Wang and Chueh (2013) who found a positive interaction between gold and oil prices for the period 1989-2007.

One possible argument states that a rising oil price is bad for the economy, dampening growth and dropping stock prices, so investors look for alternative assets such as gold. Thus, oil price indirectly affects the price of gold. Indeed, both oil and gold trade is invoiced in the USD. Therefore, their pricing process depends on the strength of that currency, as driven by its inflation rate. It can be argued that sharing similar behavior is not because one influences the other, but because their prices are driven by a common factor: the US inflation rate. A noteworthy finding that gold and USD move inversely. This finding implies that the global price of gold should not be used for hedging 
individual currency risk.

Exchange rate movements during the global financial crisis of 2007-2009 were unusual. Unlike in two previous episodes - the Asian crisis of 1997-1998 and the crisis following the Russian debt default in 1998, in 2008 a large number of currencies depreciated sharply even though they were not at the center of the crisis. Moreover, in 2009, the crisis-related movements reversed strongly for some countries. Our research gives a new insight into the behavior between oil, gold, and USD exchange rates during the pre-crisis, crisis and post-crisis period, thus leading to significant implications for policy makers, investors and risk managers. 


\section{References}

Akram, Q.F., (2009) ,Commodity prices, interest rates and the dollar., Energy Economics 31, 838-851.

Aloui,R.,Ben Assa, M.S.,\& Nguyen,D.K.,(2011), Global financial crisis, extreme interdependence, and contagion effects: the role of economic structure., Journal of Banking and Finance 35, 130-141.

Aloui,R.,Ben Assa, M.S.,\& Nguyen,D.K.,(2013),Conditional dependence structure between oil prices and exchange rates: A copula-GARCH approach., Journal of International Money and Finance 32, 719-738.

Amano, R \& van Norden, S., (1998), Oil prices and the rise and fall of the US real exchange rate. , Journal of International Money and Finance 17 (2), 299-316.

Arouri, M.E.H.\& Nguyen, D.K., (2010), Oil prices, stock markets and portfolio investment: evidence from sector analysis in Europe over the last decade. Energy Policy 38, 4528-4539.

Arouri, M.E.H,Dinh, T.H.\& Nguyen, D.K., (2010), Time-varying predictability in crude-oil markets: the case of GCC countries., Energy Policy 38, 4371-4380.

Adrian W. Throop, (1993), "A generalized uncovered interest parity model of exchange rates, Economic Review, Federal Reserve Bank of San Francisco, pages 3-16.

Baffes, J.,(2007) ,Oil spills on other commodities., Resources Policy 32,126134.

Baillie, R.T.,Bollerslev, T.\& Mikkelsen, H.O., (1996). ,Fractionally integrated generalized autoregressive conditional heteroskedasticity., Journal of Econometrics 74, 3-30.

Baur, D.G.\& Lucey,B.M.,(2010) ,Is gold a hedge or a safe haven?, Analysis of stocks, bonds and gold, Financial Review 45,217-229.

Baur, D.G.,\& McDermott,T.K.,(2010) ,Is gold a safe haven?, International evidence, Journal of Banking and Finance 34,1886-1898.

Blose, L.E.,(2010)., Gold prices, cost of carry, and expected inflation., Journal of Economics and Business 62(1),35-47.

Bollerslev, T., (1986)., Generalized autoregressive conditional heteroskedasticity., Journal of Econometrics 31, 307-327.

Bollerslev, T., (1987), A conditionally heteroskedastic time series model for speculative prices and rates of return., Review of Economics and Statistics 69, 542-547.

Bollerslev, T.\& Mikkelsen, H., (1996), Modeling and pricing long memory in stock market volatility., Journal of Econometrics 73 (1),151-184.

Bowden, N.\& Payne,J.E.,(2008), Short term forecasting of electricity prices for MISO hubs:evidence from ARIMA-EGARCH models., Energy Economics 30, 3186-3197.

Breymann,W.,Dias,A.\& Embrechts,P.,(2001), Dependence structures for multivariate highfrequency data in finance., Quantitative Finance 3,1-16.

Capie, F.,Mills,T.C.,\& Wood,G.,(2005), Gold as a hedge against the dollar., Journal of International Financial Markets, Institutions and Money 15,343-352.

Chan-Lau, J.A.,Mathieson, D.J.\& Yao, J.Y., (2004), Extreme contagion in equity markets., IMF Staff Papers 51 (2), 386-408.

Chen, S.S.\&Chen, H.C., (2007), Oil prices and real exchange rates., Energy Economics 29 (3), 390-404.

Cherubini, U., Luciano, E. \& Vecchiato, W., (2004)., Copula Methods in Finance., John Wiley \& Sons Ltd.

Clayton, D.G., (1978), A model for association in bivariate life tables and its application in epidemiological studies of familial tendency in chronic disease incidence, Biometrika 65, 141-152.

Cologni, A. \& Manera, M., (2009), The asymmetric effects of oil shocks on output growth: a Markov-switching analysis for the G-7 countries., Economic Modelling 26, 1-29.

Cousin, A. and E. Di Bernardino (2013), On multivariate extensions of VaR, Journal of Multivariate Analysis, 119, 32-46.

Deheuvels, P. (1978). Caracterisation complete des lois extremes multivariees et de la convergence 
des types extremes. Publ. Inst. Statist. Univ. Paris, 23, 1-36.

Dibooglu, S., (1996), Real disturbances, relative prices, and purchasing power parity., Journal of Macroeconomics 18 (1), 69-87.

Fama, E.F., (1965)., The behavior of stock market prices., Journal of Business 38, 34-105.

Fayyad, A.\&Daly, K., (2011, The impact of oil price shocks on stock market returns: comparing GCC countries with the UK and USA., Emerging Markets Review 12, 61-78.

Genest, C., Ghoudi, K.,\& Rivest, L.-P., (1995), A semi-parametric estimation procedure of dependence parameters in multivariate families of distributions., Biometrika 82, 543-552.

Genest, C., Remillard, B.\& Beaudoin, D., (2009), Goodness-of-fit tests for copulas: a review and a power study., Insurance: Mathematics and Economics 44, 199-213.

Golub, S., 1983, Oil prices and exchange rates., The Economic Journal 93, 576-593.

Green, S.L.\& Mork, K.A. (1991), Toward efficiency in the crude-oil market., Journal of Applied Econometrics 6, 45-66.

Gregoire, V., Genest, C.\& Gendron, M., (2008), Using copulas to model price dependence in energy markets., Energy Risk 5, 58-64.

Gumbel, E.J., (1960), Bivariate exponential distributions., Journal of the American Statistical Association 55, 698-707.

Hamilton, J.D., (1983), Oil and the macroeconomy since World War II, Journal of Political Economy 99 (2), 228-248.

Hammoudeh, S.\& Yuan, Y (2008), Metal volatility in presence of oil and interest rate shocks, Energy Economics 30(2), 606-620.

Hansen, B., (1994), Autoregressive conditional density estimation., International Economic Review 35 (4), 705-730.

Hooker, M.A., (1996)., What happened to the oil price macroeconomy relationship?, Journal of Monetary Economics 38, 195-213.

Joe, H., (1997)., Multivariate Models and Dependence Concepts., Chapman \& Hall/CRC, London, UK.

Joe, H.\& Xu,J.J.,(1996)., The estimation method of inference functions for margins for multivariate models., Technical Reportno.166. Department of Statistics. University of British Columbia, USA

Joy, M.,(2011)., Gold and the US dollar,hedge or haven?, Finance Research Letters 8, 120-131.

J.-M. Kim and H. Jung (2017)., Can Asymmetric Conditional Volatility Imply Asymmetric Tail Dependence?, Economic Modeling, 64, 409-418.

J.-M. Kim, and H. Jung (2016)., Linear Time Varying Regression with Copula DCC-GARCH Model for Volatility., Economics Letters, 145, 262-265

Kojadinovic, I., Yan, J., \& Holmes M. (2011)., Fast large-sample goodness-of-fit tests for copulas., Statistica Sinica 21, 841-871.

Kojadinovic, I. \& Yan, J. (2010)., Modeling Multivariate Distributions with Continuous Margins Using the copula $R$ Package., Journal of Statistical Software 34(9),1-20.

Kojadinovic, I.\& Yan, J., (2011), A goodness-of-fit test for multivariate multiparameter copulas based on multiplier central limit theorems., Statistics and Computing 21 (1), 17-30.

Mandelbrot, B., (1963)., The variation in certain speculative prices., Journal of Business 36,394419

Mashal, R., Naldi, M.\& Zeevi, A., (2003)., On the dependence of equity and asset returns., Risk 16, 83-87

Mork, K., (1989)., Oil and the macro-economy, when prices go up and down: an extension of Hamiltons results, Journal of Political Economy 97, 740-744

Narayan, P.K., Narayan, S.\& Prasad, A., (2008)., Understanding the oil price-exchange rate nexus for the Fiji islands., Energy Economics 30, 2686-2696.

Nelsen, R.B., (1999)., An Introduction to Copulas., Springer, New York, USA.

Nelson, D.B., (1991)., Conditional heteroskedasticity in asset returns: a new approach, Econometrica 59, 347-370 
Park, J.W.\& Ratti, R.A., (2008)., Oil price shocks and stock markets in the U.S. and 13 European countries, Energy Economics 30 (5), 2587-2608

Plackett, R.L., (1965)., A class of bivariate distributions, Journal of the American Statistical Association 60, 516-522

Plourde, A.\& Watkins, G.C., (1998)., Crude oil prices between 1985 and 1994: how volatile in relation to other commodities?, Resource and Energy Economics 20, 245-262.

A. Pourkhanali, J.-M. Kim, L. Tafakori and F. A. Fard (2016)., Measuring Systemic Risk Using Vine-Copula., Economic Modeling, 53, 63-74

Reboredo, JC. (2013)., Is gold a hedge or safe haven against oil price movements?, Resources Policy 38, 130-137.

Regnier, E., (2007)., Oil and energy price volatility., Energy Economics 29, 405-427

Roch, O., Alegre, A., (2006)., Testing the bivariate distribution of daily equity returns using copulas: an application to the Spanish stock market, Computational Statistics \& Data Analysis 51 (2), 1312-1329.

Rogoff, K., (1991)., Oil, Productivity, Government Spending and the Real Yen-dollar Exchange Rate., Working Paper, No. 9106. Federal Reserve Bank of San Francisco, San Francisco, California, USA.

Sadorsky, P., (2001)., Risk factors in stock returns of Canadian oil and gas companies., Energy Economics 23, 17-28.

Sari, R.,Hammoudeh,S. \& Soytas , U (2010), Dynamics of oil price, precious metal prices, and exchange rate., Energy Economics, 32(2),351-362

Serra, T., 2011., Volatility spillovers between food and energy markets: a semiparametric approach., Energy Economics 33,1155-1164.

Shambora,W.E.\& Rossiter, R., (2007)., Are there exploitable inefficiencies in the futures market for oil?, Energy Economics 29, 18-27.

Sifneos, P. E. (1960). A concept of 'emotional crisis'. Mental Hygiene, 44, 169.

Subarna, K.S. and Zadeh Ali, H.M. (2015), Co-Movements of Oil, Gold, the US Dollar and Stocks, Modern Economy, 3, 111-117.

Theodossiou, P., (2000)., Skewed Generalized Error Distribution of Financial Assets and Option Pricing., Working Paper. School of Business, Rutgers University, USA.

Wang, Y. S., and Chueh, Y. L. (2013). Dynamic transmission effects between the interest rate, the US dollar, and gold and crude oil prices. Economic Modelling, 30, 792-798.

Wu, C.C., Chung, H., and Chang, Y.H., (2012)., The Economic Value of Co-movement between Oil Price and Exchange Rate Using Copula-based GARCH Models., Energy Economics, 34 (1), 270-282.

Zhang, D., (2008)., Oil shock and economic growth in Japan: a nonlinear approach., Energy Economics 30, 2374-2390.

Zhang, Y.-J., Fan, Y., Tsai, H.-T.\& Wei, Y.-M., (2008)., Spillover effect of US dollar exchange rate on oil prices., Journal of Policy Modeling 30, 973-991.

Zhang, H.J., Dufour, J. and Galbraith, J.W. (2016), Exchange Rates and Commodity Prices: Measuring Causality at Multiple Horizons, Journal of Empirical Finance, 36, 100-120.

Zhou, S(1995), The Response of Real Exchange Rates to Various Economic Shocks., Southern Economic Journal 61(4), 936-954. 


\section{$6 \quad$ Appendices}

\section{A.Tables}

Table 10:Euro GJR-GARCH Estimation.

\begin{tabular}{|l||c|c|c|c|}
\hline & Coefficient & Std.Error & t-value & t-prob \\
\hline Cst $(\mathrm{M})$ & 0.0000827 & $0.7737 \mathrm{e}-005$ & 1.049 & 0.2942 \\
\hline$A R(1)$ & -0.008608 & 0.013911 & -0.6188 & 0.5361 \\
\hline$\omega \times 10^{6}$ & 0.066691 & 0.046997 & 1.419 & 0.1560 \\
\hline$A R C H(\alpha)$ & 0.025312 & 0.0052200 & 4.849 & 0.0000 \\
\hline$G A R C H(\beta)$ & 0.968034 & 0.0040089 & 241.5 & 0.0000 \\
\hline$G J R(\gamma)$ & 0.011444 & 0.0062151 & 1.841 & 0.0656 \\
\hline$v$ & 7.572895 & 0.86241 & 8.781 & 0.0000 \\
\hline
\end{tabular}

Table 11 :CHF GJR-GARCH Estimation.

\begin{tabular}{|l||c|c|c|c|}
\hline & Coefficient & Std.Error & t-value & t-prob \\
\hline Cst $(\mathrm{M})$ & -0.0000418 & $0.1541 \mathrm{e}-005$ & -0.4998 & 0.6172 \\
\hline$A R(1)$ & -0.030798 & 0.014073 & -2.188 & 0.0287 \\
\hline$\omega \times 10^{6}$ & 0.396585 & 0.13218 & 3.000 & 0.0027 \\
\hline$A R C H(\alpha)$ & 0.035145 & 0.0072985 & 4.815 & 0.0000 \\
\hline$G A R C H(\beta)$ & 0.953471 & 0.0065139 & 146.4 & 0.0000 \\
\hline$G J R(\gamma)$ & 0.005913 & 0.0095153 & 0.6214 & 0.5344 \\
\hline$v$ & 5.812659 & 0.62836 & 9.250 & 0.0000 \\
\hline
\end{tabular}

Table 12 :GBP GJR-GARCH Estimation.

\begin{tabular}{|l||c|c|c|c|}
\hline & Coefficient & Std.Error & t-value & t-prob \\
\hline$C \operatorname{st}(M)$ & 0.0000677 & $0.4172 \mathrm{e}-005$ & 0.9004 & 0.3680 \\
\hline$A R(1)$ & 0.012543 & 0.014357 & 0.8737 & 0.3824 \\
\hline$\omega \times 10^{6}$ & 0.223946 & 0.088636 & 2.527 & 0.0116 \\
\hline$A R C H(\alpha)$ & 0.030920 & 0.0083086 & 3.721 & 0.0002 \\
\hline$G A R C H(\beta)$ & 0.954387 & 0.0080183 & 119.0 & 0.0000 \\
\hline$G J R(\gamma)$ & 0.015872 & 0.0092708 & 1.712 & 0.0870 \\
\hline$v$ & 8.301206 & 1.2025 & 6.904 & 0.0000 \\
\hline
\end{tabular}


Table 13 :CAD GJR-GARCH Estimation.

\begin{tabular}{|l||c|c|c|c|}
\hline & Coefficient & Std.Error & t-value & t-prob \\
\hline$C \operatorname{st}(M)$ & -0.0000166 & $0.6948 \mathrm{e}-005$ & -0.2412 & 0.8094 \\
\hline$A R(1)$ & 0.002606 & 0.014346 & 0.1816 & 0.8559 \\
\hline$\omega \times 10^{6}$ & 0.126686 & 0.046455 & 2.727 & 0.0064 \\
\hline$A R C H(\alpha)$ & 0.044314 & 0.0085108 & 5.207 & 0.0000 \\
\hline$G A R C H(\beta)$ & 0.958040 & 0.0053640 & 178.6 & 0.0000 \\
\hline$G J R(\gamma)$ & -0.010631 & 0.0093130 & -1.141 & 0.2537 \\
\hline$v$ & 7.130939 & 0.88746 & 8.035 & 0.0000 \\
\hline
\end{tabular}

Table 14 :GOLD GJR-GARCH Estimation.

\begin{tabular}{|l||c|c|c|c|}
\hline & Coefficient & Std.Error & t-value & t-prob \\
\hline$C \operatorname{st}(M)$ & 0.000360 & 0.00012329 & 2.923 & 0.0035 \\
\hline$A R(1)$ & -0.040537 & 0.014725 & -2.753 & 0.0059 \\
\hline$\omega \times 10^{4}$ & 0.013744 & 0.0034907 & 3.937 & 0.0001 \\
\hline$A R C H(\alpha)$ & 0.079299 & 0.010792 & 7.348 & 0.0000 \\
\hline$G A R C H(\beta)$ & 0.933732 & 0.0081920 & 114.0 & 0.0000 \\
\hline$G J R(\gamma)$ & -0.045710 & 0.010857 & -4.210 & 0.0000 \\
\hline$v$ & 5.412206 & 0.47564 & 11.38 & 0.0000 \\
\hline
\end{tabular}

Table 15 :WTI GJR-GARCH Estimation.

\begin{tabular}{|l||c|c|c|c|}
\hline & Coefficient & Std.Error & t-value & t-prob \\
\hline$C \operatorname{st}(M)$ & 0.000579 & 0.00026817 & 2.160 & 0.0309 \\
\hline$A R(1)$ & -0.033777 & 0.015073 & -2.241 & 0.0251 \\
\hline$\omega \times 10^{4}$ & 0.022150 & 0.0091038 & 2.433 & 0.0150 \\
\hline$A R C H(\alpha)$ & 0.023934 & 0.0069279 & 3.455 & 0.0006 \\
\hline$G A R C H(\beta)$ & 0.953282 & 0.0065323 & 145.9 & 0.0000 \\
\hline$G J R(\gamma)$ & 0.037845 & 0.0097265 & 3.891 & 0.0001 \\
\hline$v$ & 6.362070 & 0.59851 & 10.63 & 0.0000 \\
\hline
\end{tabular}

Table 16 :Brent GJR-GARCH Estimation.

\begin{tabular}{|l||c|c|c|c|}
\hline & Coefficient & Std.Error & t-value & t-prob \\
\hline$C s t(M)$ & 0.000334 & 0.00025792 & 1.296 & 0.1951 \\
\hline$A R(1)$ & 0.017050 & 0.013960 & 1.221 & 0.2220 \\
\hline$\omega \times 10^{4}$ & 0.007360 & 0.0046681 & 1.577 & 0.1149 \\
\hline$A R C H(\alpha)$ & 0.015274 & 0.0061041 & 2.502 & 0.0124 \\
\hline$G A R C H(\beta)$ & 0.966188 & 0.0067190 & 143.8 & 0.0000 \\
\hline$G J R(\gamma)$ & 0.035444 & 0.0086080 & 4.118 & 0.0000 \\
\hline$v$ & 6.468287 & 0.63422 & 10.20 & 0.0000 \\
\hline
\end{tabular}

